NBER WORKING PAPER SERIES

AN INFORMATION APPROACH TO INTERNATIONAL CURRENCIES

\author{
Richard K. Lyons \\ Michael J. Moore \\ Working Paper 11220 \\ http://www.nber.org/papers/w11220 \\ NATIONAL BUREAU OF ECONOMIC RESEARCH \\ 1050 Massachusetts Avenue \\ Cambridge, MA 02138 \\ March 2005
}

Lyons' affiliations are U.C. Berkeley and NBER and Moore's is Queen's University Belfast m.moore@qub.ac.uk). We thank the following for valuable comments: Philipp Hartmann, Hélène Rey, Dagfinn Rime, Cedric Tille, and seminar participants at U.C. Berkeley, LSE, and the Stockholm conference on Microstructure Analysis in International Macro (April 2003). Lyons thanks the National Science Foundation for support, which includes a web clearinghouse for micro-based exchange rate research (at faculty.haas.berkeley.edu/lyons). The views expressed herein are those of the author(s) and do not necessarily reflect the views of the National Bureau of Economic Research.

(C) 2005 by Richard K. Lyons and Michael J. Moore. All rights reserved. Short sections of text, not to exceed two paragraphs, may be quoted without explicit permission provided that full credit, including () notice, is given to the source. 
An Information Approach to International Currencies

Richard K. Lyons and Michael J. Moore

NBER Working Paper No. 11220

March 2005

JEL No. F3, F4, G1

\begin{abstract}
This paper addresses currency competition from an information perspective. Transactions in traditional models do not convey information, so transaction costs - the driver of competition outcomes - are driven by market size. In our model transactions do convey information (consistent with recent empirical findings). Several important departures arise. First, adding the information dimension resolves the traditional indeterminacy of currency trade patterns (by mitigating the concentrating force of market-size economies). Second, whether transactions are executed directly or through a vehicle actually affects prices (because these trading methods do not in general reveal the same information). Third, our model provides a new rationale for why some currency pairs never trade directly (information is not sufficiently symmetric to support trading). Fourth, our model formalizes the arbitrage process and shows that arbitrage transaction quantities and price levels are jointly determined. Empirically, the paper provides a first integrated analysis of transactions in a triangle of markets: $¥ / \$, \$ / €$, and $¥ / €$. Data for the full triangle permits comparison of direct, indirect and arbitrage transactions, for each pair. The information model predicts that transactions should affect prices across markets (e.g., flow in the $¥ / \$$ market should convey information relevant to $\$$ / $€$ and $¥ / €$ prices), which is borne out.
\end{abstract}

\author{
Richard K. Lyons \\ Haas School of Business \\ University of California, Berkeley \\ Berkeley, CA 94720-1900 \\ and NBER \\ lyons@haas.berkeley.edu \\ Michael J. Moore \\ Queen's University \\ m.moore@qub.ac.uk
}




\section{An Information Approach to International Currencies}

Why do people choose one country's money over another's? The question's empirical relevance is clear: different monies play very different roles internationally. For example, the current roles of the U.S. dollar and Swiss franc are disproportionately large, whereas the roles of the Japanese yen and European euro are disproportionately small (proportions based on, for example, economic size). This paper addresses an important dimension of this internationalcurrency question, namely cross-currency exchange. Why are some currencies foci in the pattern of currency exchange, while others remain peripheral? Our answer involves not only currencies' medium-of-exchange function, but also, critically, their store-of-value function (the latter via currency-denomination of portfolio choices).

Our approach is radically different from the two existing approaches. The focus of the earliest approach is on currency market size (Krugman 1980). The basic idea underlying the market-size approach is that transaction costs in a bilateral market are a decreasing function of the total volume traded. Krugman is agnostic about the mechanism underlying the transaction cost effect. His focus is instead on the increasing returns (and multiple equilibria) that result from market-size economies: the choice to trade particular currencies has effects on transaction costs that promote further trade in those currencies, and vice versa. The market-size approach was much enriched by Matsuyama et al. (1993), Zhou (1997), and Rey (2001), who use a searchtheoretic basis for why transaction costs should decrease with market size. ${ }^{1}$ The work of Rey is particularly relevant in that she specifically analyzes the existence and use of vehicle currencies (i.e., currencies used in the indirect exchange of two other currencies by means of two offsetting transactions). That vehicle currencies can, and indeed generally must, arise is central to understanding equilibrium patterns of currency exchange (a point stressed by Krugman).

The second main approach to modeling patterns of currency exchange is the marketmaker-risk approach (Black 1991 and Hartmann 1998). This approach adds exchange rate volatility to the determinants of transaction costs. When exchange rates are more volatile, the risk faced by liquidity-providing marketmakers increases, inducing them to increase the transaction spread they receive as compensation. ${ }^{2}$ Models in this second approach highlight the importance of

\footnotetext{
${ }^{1}$ The search-theoretic basis for transaction costs that decrease with market size is not the only possible basis. For example, fixed costs to marketmaking will also produce declining costs as market size grows.

${ }^{2}$ Models of marketmaker risk and its effect on transaction costs launched a sub-field of finance in the 1970s called microstructure (see, e.g., Garman 1976 and Stoll 1978).
} 
exchange rate second moments in determining currency exchange patterns, a significant point that was absent in the earlier literature.

The approach to international currencies in this paper is instead information based. The basic idea is that when transactions convey information, then the cost of effecting those transactions will be an increasing function of the information they convey (which in turn feeds back into the currencies people choose to trade). This mechanism is well known within the theoretical literature on informative trading (e.g., Copeland and Galai 1983, Kyle 1985, and Glosten and Milgrom 1985). It has not been used to model patterns of currency exchange, however. A fundamental idea that comes from these information models is that one cannot simply use posted bid-ask spreads - which generally apply to smaller transactions - as a measure of transaction costs. Rather, what matters is the price impact of trades, i.e., if one wants to establish or liquidate a large position, at what price will the last bits be executed? This is a richer (and more realistic) way of thinking about effective transaction costs. In this setting, the percentage cost of individual trades increases with size (i.e., transactable prices are sloping schedules, not single bid and ask prices good for any quantity, as would be the case under proportional costs). In contrast, the costs of transacting in the two existing approaches are assumed proportional-individual transactions generate no economies or diseconomies.

Why do we choose this approach and why does it matter? Consider first our choice. It is motivated on both empirical and theoretical grounds. Empirically, a recent series of papers at both the micro (i.e., individual marketmaker) and market-wide levels has established that foreign exchange transactions do indeed convey information that affects price (e.g., Lyons 1995, Rime 2001, Killeen et al. 2001, Covrig and Melvin 2002, Evans and Lyons 2002a,b, Payne 2003, Bjonnes and Rime 2003). Not only are these effects present, they are large: they can account for 40-80 percent of the daily variation in major rates (Evans and Lyons 2002b). ${ }^{3}$ This empirical perspective was not present at the time the two earlier approaches to international currencies were developed.

Theoretical motivation for our information approach includes two main elements. The first relates to the nature of the information conveyed by transactions and why, theoretically, this role for transactions makes sense. For information models to be relevant to FX it is not necessary that private information be of the "concentrated" type, e.g., inside information in the hands of one or a few individuals (regarding some macro variable). Rather, our information model is consistent with an economic environment where information is of the "dispersed" type, i.e., in which there

\footnotetext{
${ }^{3}$ Moreover, daily exchange rates are very nearly a random walk, which means this accounted-for variation is very persistent.
} 
are myriad bits of information relevant to exchange rates that are not observable to all agents and need to be aggregated via market processes. Think, for example, about heterogeneous shifts in money demands or risk preferences, both of which will produce currency transactions that, in turn, inform the market about those shifts.

The second theoretical motivation for our approach is linked to cross-sectional (versus time-series) variation in information environments. Specifically, our model helps identify information differences across bilateral markets that can drive currency competition outcomes. Hartmann (1998) recognizes the possibility of modeling currency exchange using an information approach, but argues that "information-cost effects are transitory and therefore less relevant for the emergence of vehicle currencies" (page 43, footnote 3). The Hartmann argument against information-based analysis is a time-series argument: the information-cost effects he is considering are due to shocks to trading volume over time. Our focus here, in contrast, is on cross-sectional differences among markets. Cross-sectional differences are by their nature persistent. ${ }^{4}$ They include any variables that affect the per-dollar information intensity of flows in a given market. Examples include the relative concentration of marketmaking, the relative importance of currency transactions tied to real trade, and the relative slopes of the markets' net excess supply curves (i.e., the relative elasticity of economy-wide liquidity provision in the two markets). ${ }^{5}$ These variables - as well as many others - affect the signal-to-noise ratio in flows, which translates into cross-market differences in transaction costs. For concreteness, consider the first of these examples in more detail. Suppose there are two currency markets, one in which the three largest marketmaking banks enjoy an 80 percent market share (i.e., they observe 80 percent), the other in which the three largest marketmaking banks enjoy a 20 percent market share. Given that currency transaction flows convey information, and given that transaction flows are not observable to all participants, the result is cross-market differences in information symmetry.

Analytical results from our information model include several important departures from traditional results. First, adding the information dimension resolves the traditional indeterminacy of currency trade patterns. The reason is that the convex trading costs faced by individual agents mitigate the concentrating force of market-size economies (the latter being the focus of Krugman

\footnotetext{
${ }^{4}$ That the time-series of information effects should be associated with unexpected trading volume, as argued by Hartmann (1998), is not always true as a theoretical matter. For example, in the Kyle-model framework we use here, unexpectedly high volume has no additional information content, dollar for dollar (i.e., the parameter governing the price impact of a dollar of order flow is not a function of realized volume). For evidence on persistent cross-sectional differences in the information environments of individual stocks, see Easley, Hvidkjaer, and O'Hara (2002).

${ }^{5}$ See Hau and Rey (2002) for analysis of how supply curve slopes affect exchange rate determination.
} 
1980). Second, the pattern of currency trade is not driven by the pattern of real trade, as it is in traditional models (e.g., Krugman 1980 and Rey 2001), but instead by the pattern of asset trade. It is well known that currency trade resulting from underlying real trade accounts for less than 5 percent of trading volume in the major currency markets (though this number was much higher in the pre-1950 period when sterling was the world's dominant currency). ${ }^{6}$ Third, exchange rate levels are actually affected by whether transactions are executed directly or indirectly. This is because these trading methods do not in general reveal the same information (i.e., the equilibrium price impact from the two indirect trades does not in general equal the price impact from the equivalent direct trade). Fourth, our model provides a new rationale for why some currency pairs never trade directly: in information models of the type we analyze here, if the information available to various market participants is not sufficiently symmetric, then the market breaks down - there is insufficient incentive to participate (see, e.g., Bhattacharya and Spiegel 1991 and the earlier literature on "no-trade theorems", e.g., Milgrom and Stokey 1982). The conditions in our model that lead to the absence of direct trade — what Krugman calls total indirect exchangeare of a completely different nature than those outlined by Krugman.

By modeling currency exchange patterns using a pure information model, we do not mean to imply that market size and volatility - the driving forces in the two earlier approachesare irrelevant. Size and volatility are definitely relevant. Rather, our objective is to learn what we can from a pure information model, given it has never been addressed in the literature, and given the strong empirical motivation for doing so.

Our empirical analysis is the first integrated analysis of transactions in a triangle of markets: $¥ / \$, \$ / €$, and $¥ / € .^{7}$ Data on the full triangle permits comparison of direct and indirect exchange for each (e.g., $¥ / \$ \times \$ / €=¥ / €)$. We also formalize the incentives to engage in triangular arbitrage. Unlike the traditional market-size approach, our information model predicts that transactions should affect prices across markets (e.g., flow in the $\$ / €$ market should convey information relevant to $¥ / €$ and $¥ / \$$ prices). This prediction is borne out.

The remainder of the paper is organized as follows. Section I presents our model of how information transmission affects currency exchange patterns. Section II extends the model to address vehicle currency determination. Section III presents supporting empirical work. Section IV concludes.

\footnotetext{
${ }^{6}$ To be fair, the Rey (2001) and Krugman (1980) models can also serve as metaphors for countries' balance-of-payments accounts more broadly (i.e., not just real trade, but also the capital account). But even the sum of capital-account transactions and those from real trade is far too low to account for FX volume. ${ }^{7}$ Danielsson, Payne, and Luo (2002) analyze data for a full currency-market triangle, but treat each of the three markets separately (i.e., there is no integration of triangular arbitrage into their order flow model).
} 


\section{An Information Model of Currency Exchange Patterns}

This section develops a model for analyzing direct versus indirect currency exchange. The basic structure is simple, drawing on the Kyle (1985) order flow model. ${ }^{8}$ Though simple, our model is rich enough to embed the cross-market information links that are particular to FX. Information links across markets arise in the model because order flow in one market conveys information relevant for the pricing of the other exchange rates. This information relates to fundamental cash flows and is conveyed by the trades of agents who have amassed superior information of this type (e.g., through observation of market transaction flows correlated with future cash flows, but not yet fully impounded in price). Though there is an existing multi-market version of the Kyle model in the literature (Chowdhry and Nanda 1991), it does not include the triangular parity relationships across markets that are our focus here. Indeed, to our knowledge our model is the first trading model to address these issues.

There is another feature of the forex market that motivates our use of the Kyle (1985) framework. Aggregation of dispersed information takes time. During that time some participants (e.g., commercial banks with large forex customer bases) are observing informative transaction flows before this information is fully impounded in price, which results in information advantages becoming increasingly concentrated. This squares with the strategic informed trading that is the hallmark of Kyle-type models. Do the largest players in this market (e.g., large commercial banks, hedge funds) in fact trade strategically in order to minimize their price impact? For anyone who has observed these markets, the answer is a clear yes. This is precisely what the Kyle model is designed to capture.

\section{Payoffs, information, and triangular parity}

There are three markets in the model: market 1 (for concreteness, $\$(€)$, market $2(¥ / \$)$, and market $3(¥ / €)$. Let $p^{1}, p^{2}$, and $p^{3}$ denote the change in the log of prices in the three markets, measured as dollars per euro, yen per dollar, and yen per euro, respectively. If triangular parity were to hold (i.e., no triangular arbitrage opportunities), the following would also be an identity:

\footnotetext{
${ }^{8}$ There is an important distinction between the "flow approach" adopted by Krugman (1980) and the central role of "order flow" in Kyle-type models. Krugman is apologetic, writing that his use of flow demands and supplies in determining exchange rates is motivated by tractability and that his analysis "should therefore be regarded as preliminary". The only currency flows arising in the Krugman model are those from real trade flows, i.e., there are no agents in the model concerned about their total stock of holdings, and therefore nothing to ensure that all stocks are willingly held (stock equilibrium). Flows determine prices in the Kyle model as well, but there are agents who are optimizing over cumulated stocks. Thus, despite the central role played by (order) flow, the Kyle model is consistent with stock equilibrium.
} 


$$
p^{3}=p^{1}+p^{2}
$$

As will be clear below, this relationship is not as trivial in the micro context as it is assumed to be in international macroeconomics. In particular, the issue of how triangular parity is actually achieved needs to be addressed. For part of the market, this is an irrelevant point because most minor currencies have inter-dealer markets with only one other currency, usually the dollar. ${ }^{9}$ Cross-rates to currencies other than the dollar are then arithmetically calculated using indirect rates. However, the yen, sterling and Swiss franc all have independent inter-dealer markets with both the dollar and the euro. The seven currency pairs in these triangles constitute $70 \%$ of the total world market (BIS, 2004). ${ }^{10}$

The first point to note is that as an empirical matter, exact triangular parity in these pairs does not hold at every instant. To see this, we show the deviation from parity in Figure $1 .{ }^{11}$ Figure 1 plots the euro/yen exchange rate calculated indirectly (i.e., via a transaction through the dollar) as a ratio of the direct euro/yen rate. Though the mean is nearly unity (no deviation), the range is from +34 basis points to -30 basis points, with a standard deviation of nearly 7 basis points. For comparison, average bid-ask spreads for brokered inter-dealer trades around that time were roughly 1,1 , and 3 basis points for $€ / \$, \$ / ¥$ and $€ / ¥$, respectively. ${ }^{12}$ That triangular parity does not hold at every instant has already been observed by De Jong, Mahieu, and Schotman (1998) using high-frequency data from the Reuters FXFX system. They model adjustment to triangular parity in the $\$, ¥, \mathrm{DM}$ triangle as an error correction mechanism, but do not explore behavioral aspects of the disparity. The work of Evans (2002) is perhaps even more compelling in this regard: looking within a single market $(\mathrm{DM} / \$)$, he finds that prices exhibit significant dispersion that is purely cross-sectional (using four months of ultra-high frequency transactions data).

Let $v^{1}$ denote the innovation in the fundamental value of the bilateral $\$ / €$ pair (i.e., terminal payoff, measured as dollars per euro). Analogously, $v^{2}$ is the innovation in the fundamental value for the bilateral $¥ / \$$ pair (yen per dollar) and $v^{3}$ is the innovation in the fundamental value for the bilateral $¥ / €$ pair (yen per euro). The value innovations are i.i.d. Normal, with mean zero and scalar variance $\Sigma_{v}$.

\footnotetext{
${ }^{9}$ For the Scandinavians and the ten new members that joined the EU in May 2004, it is the euro.

${ }^{10}$ The seven pairs are USD/EUR, USD/JPY, USD/GBP, USD/CHF, EUR/JPY, EUR/GBP and EUR/CHF.

${ }^{11}$ The data cover all of 1999, sampled daily at 9pm GMT (when the trading day in New York winds down). The source is Olsen \& Associates, Zurich; we are grateful to Richard Olsen for his generosity. Importantly, these data were prepared with full knowledge of how they were going to be used, i.e., with an eye toward eliminating any non-synchronization problems.

${ }^{12}$ See Hau, Killeen and Moore (2002b), Table 3. Data are from August 1999.
} 


\section{Timing}

The trading day is divided into three events (more on notation and specifics below). ${ }^{13}$ First, the informed traders observe the value innovation $v^{j}$ in their respective market. Second, orders are submitted by both informed traders $\left(x^{j}\right)$ and liquidity-motivated traders $\left(c^{j}\right)$, where a positive order denotes a purchase and a negative order denotes a sale. Third, marketmakers set prices to clear markets based on the orders submitted and based on any information conveyed by those orders.

\section{Figure 1}

Sequence of Events in Each Market

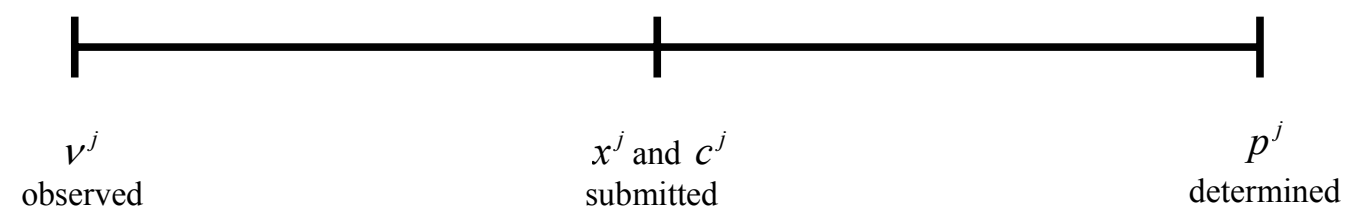

We now describe each of these three agent types - marketmakers, liquidity traders, and informed traders.

\section{Marketmakers}

The three marketmakers are competitive (meaning they expect to earn zero profit) and riskneutral. Marketmakers cannot distinguish between trader types (i.e., they observe the sum of all orders submitted, not the components separately). Because competition ensures that each marketmaker sets price such that expected profit is zero, marketmakers will necessarily set price at their expectation of the fundamental value conditional on order flows observed. Though the three marketmakers may see each others' order flows, the assumption that innovations are orthogonal means that only own-order flow is relevant for price setting. Order flow in another market conveys no additional information. This is the inference problem they must solve.

\footnotetext{
${ }^{13}$ Our empirical analysis is at the daily frequency, so it is not important for our model to capture intraday variation in liquidity (e.g., by including multiple intraday trading rounds for each trader type).
} 


\section{Liquidity traders}

There are three aggregate liquidity trades, one in each of the three markets, which are random and exogenous. (These can represent, for example, aggregations of large numbers of underlying liquidity demands in each market.) We have denoted the three aggregate liquidity trades as $c^{1}, c^{2}$, and $c^{3}$ respectively. Each of the liquidity trades is distributed Normal $\left(0, \Sigma_{c}^{j}\right)$, where $\Sigma_{c}^{j}$ is a scalar variance. The three liquidity trades and the three fundamental values are mutually independent. Note that these relative liquidity-trade variances are one way to calibrate market size (i.e., to provide links to the market-size approach to international currencies in Krugman 1980 and Rey 2001). ${ }^{14}$

\section{$\underline{\text { Informed traders }}$}

There are three risk-neutral informed traders. Each observes the realization of fundamental value in one currency pair. ${ }^{15}$ We have denoted the three informed trades as $x^{1}, x^{2}$, and $x^{3}$ respectively. The task of the informed trader is to select the size of his trade to maximise profit (which is affected by his trading costs, in the form of his trades' price impact).

To fix ideas, let us first solve for a simple version of the model in which each informed trader trades only in his own market. Since the innovations are orthogonal, a trader has no incentive to trade directly in a market in respect of which he has no information. The only type of trading that we are ruling out is arbitrage trading: this is introduced in the next section. Using the informed trader in market 1 as an example, that problem can be expressed as: ${ }^{16}$

$$
\underset{x^{1}}{\operatorname{Max}} E\left[x^{1}\left(v^{1}-p^{1}\right)\right]
$$

MM Rule:

$$
p^{1}=E\left[v^{1} \mid c^{1}+x^{1}\right]
$$

\footnotetext{
${ }^{14}$ In contrast with the market-size approach, though, expected liquidity flow in our model has no effect on prices - marketmakers simply net it out in making their inferences. Another possible link to the market-size approach would be to introduce capital constraints on informed traders, which would tend to amplify market-size effects (where size is parameterized by the liquidity-trade variances).

${ }^{15}$ This specification with the informed trader observing the fundamental value without noise follows Kyle, but need not: adding noise is straightforward but adds nothing to the economics of the problem. (The informed traders and marketmakers are risk neutral here so it is simply the expectation of fundamental value that matters for determining their decision rules.)
} 
As in the original Kyle (1985) model, we solve for the linear equilibrium. Given our assumption that liquidity trades and value innovations are Normally distributed, this gives linear pricing rules for each of the three marketmakers of the form:

$$
p^{j}=\lambda_{j}\left(c^{j}+x^{j}\right) \text { for } \mathrm{j}=1,2,3
$$

or, in matrix notation:

$$
\left[\begin{array}{l}
p^{1} \\
p^{2} \\
p^{3}
\end{array}\right]=\left[\begin{array}{ccc}
\lambda_{1} & 0 & 0 \\
0 & \lambda_{2} & 0 \\
0 & 0 & \lambda_{3}
\end{array}\right]\left[\begin{array}{c}
c^{1}+x^{1} \\
c^{2}+x^{2} \\
c^{3}+x^{3}
\end{array}\right]
$$

The solution (from Kyle) is:

$$
x^{j}=\beta_{j} v^{j} \quad \text { for } \mathrm{j}=1,2,3
$$

where:

$$
\beta_{j}=\left(\Sigma_{c j} / \Sigma_{v}\right)^{1 / 2} \quad \text { for } j=1,2,3
$$

and:

$$
\lambda_{j}=\left(2 \beta_{j}\right)^{-1} \quad \text { for } j=1,2,3
$$

We know from this equilibrium that:

$\operatorname{Var}\left[v^{j}\right]=2 \operatorname{Var}\left[v^{j} \mid c^{j}+x^{j}\right]$

And in our case we can write departures from triangular parity as:

$\operatorname{Var}\left[p^{1}+p^{2}-p^{3}\right]=\lambda_{1}^{2} \operatorname{Var}\left[c^{1}+\beta_{1} v^{1}\right]+\lambda_{2}^{2} \operatorname{Var}\left[c^{2}+\beta_{2} v^{2}\right]+\lambda_{3}^{2} \operatorname{Var}\left[c^{3}+\beta_{3} v^{3}\right]$

Since the innovations are independent, the Kyle result goings through straightforwardly: strategic trading by the informed traders cuts the variance of deviations from triangular parity in observed exchange rates to half of the variance of deviations from triangular parity in the innovations.

${ }^{16}$ Note that $v^{j}$ and $p^{j}$ are logs of their cash values, so this maximization problem involves a monotonic 


\section{Adding Vehicle Currencies}

The equilibrium above has the unappealing theoretical property that informed traders are not permitted to trade indirectly through the other two markets (sometimes called one-way arbitrage, i.e., building a position less expensively by doing the trade indirectly), nor are they able to do round-trip trades to profit from departures from triangular parity (two-way arbitrage) ${ }^{17}$. In addition, this equation has the property that order flow in each market conveys no information that is relevant for price determination in the other markets (i.e., the matrix of $\lambda$ 's in equation (4) is diagonal).

We now extend the model to allow informed agents to trade indirectly via a vehicle currency and to engage in two-way arbitrage. ${ }^{18}$ Let the subscripts $d, i$, and $a$ refer to direct, indirect, and arbitrage (two-way) trades respectively, so that $x_{\mathrm{i}}^{1}$, for example, denotes the indirect trade of the trader who is informed about the market 1 value innovation $v^{1}$. As an indirect trade, $x_{\mathrm{i}}^{1}$ is part of the order flow in both market 2 and market 3 , but not part of order flow in market 1. Other than re-specification of the informed traders' problem, the model has the same structure as that above (save, of course, that the flows that each marketmaker now sees include six components rather than two: the liquidity trade $c^{1}$ and direct informed trade $x_{\mathrm{d}}^{1}$ as before, plus an indirect and an arbitrage trade from each of the two other-market informed traders).

Though the notation above seems simple enough, it embeds a subtlety that warrants further attention. Specifically, getting the sign of the trade direction right in Kyle-type models is crucial. So, take for example the indirect trade of the informed trader in market $3, x_{i}^{3}$. When positive, this is indirect buying of euros, and paying of yen, which we refer to as "buying ¥/€”. Buying $¥ / €$ indirectly therefore involves buying $¥ / \$$ and also buying $\$ / €$, i.e., when $x_{i}^{3}>0$, then this constitutes positive order flow in both markets 1 and 2. This is not the case for indirect trading by the other two insiders, however. Consider the indirect trade of the informed trader in market $2, x_{i}^{2}$ : when positive, this is indirect buying of dollars, and paying of yen. Buying $¥ / \$$

\footnotetext{
transformation of the "price" argument.

${ }^{17}$ The distinction between one-way and two-way arbitrage is well established in international economics. It was first introduced by Deardorff (1979): it was developed by Callier (1981), Bahmani-Oskooee et al. (1985) and Clinton (1988).

${ }^{18}$ Though we do not add them here, one could also introduce strategic liquidity trading, for example, allowing the liquidity traders to trade either directly or indirectly.
} 
indirectly therefore involves buying $¥ / €$ and selling $\$ / €$, i.e., when $x_{i}^{2}>0$, this constitutes positive order flow in market 3 but negative order flow in market 1. Similarly, buying $\$ / €$ indirectly involves buying $¥ / €$ and selling $¥ / \$$, i.e., when $x_{i}^{1}>0$, this constitutes positive order flow in market 2 but negative order flow in market 1 . These same sign issues affect the two-way arbitrage trades. ${ }^{19}$ An arbitrage trade $x_{a}^{3}$ will denote a sale in market 3 , and therefore purchases in both markets 1 and 2. An arbitrage trade $x_{a}^{1}$ will denote a sale in market 1 , a purchase in market 3 , and a sale in market 2. An arbitrage trade $x_{a}^{2}$ will denote a sale in market 2, a purchase in market 3, and a sale in market 1.

The task of the informed trader is to select the size and location of his trades so as to maximise profit. This is of course affected by the extent to which the informed trader's actions move price. Each informed trader still observes the fundamental innovation in one of the three markets. When he trades indirectly, the trades he places in the other two markets eliminate any net position in the vehicle currency. (For example, the trader in the $¥ / €$ market now has the option of taking positions in $¥ / €$ indirectly via equal dollar-sized trades in the $¥ / \$$ and $\$ / €$ markets - one a dollar purchase and the other a sale, to eliminate any net dollar position. $)^{20}$ When he trades for arbitrage, the trades he places in the three markets eliminate any net position in any of the three currencies, save for any dollar profit generated from the arbitrage.

First, marketmakers set regret-free prices based on the full matrix of order flows: ${ }^{21}$

$$
\left[\begin{array}{c}
p^{1} \\
p^{2} \\
p^{3}
\end{array}\right]=\left[\begin{array}{lll}
\lambda_{11} & \lambda_{12} & \lambda_{13} \\
\lambda_{21} & \lambda_{22} & \lambda_{23} \\
\lambda_{31} & \lambda_{32} & \lambda_{33}
\end{array}\right]\left[\begin{array}{l}
c^{1}+x_{\mathrm{d}}^{1}-x_{\mathrm{i}}^{2}+x_{\mathrm{i}}^{3}-x_{\mathrm{a}}^{2}+x_{\mathrm{a}}^{3} \\
c^{2}+x_{\mathrm{d}}^{2}-x_{\mathrm{i}}^{1}+x_{\mathrm{i}}^{3}-x_{\mathrm{a}}^{1}+x_{\mathrm{a}}^{3} \\
c^{3}+x_{\mathrm{d}}^{3}+x_{\mathrm{i}}^{1}+x_{\mathrm{i}}^{2}+x_{\mathrm{a}}^{1}+x_{\mathrm{a}}^{2}
\end{array}\right]
$$

Naturally, the informed traders integrate this pricing rule into their strategy. Consider, for example, the problem for the informed trader in market 3 , the $¥ / €$ trader. He has to take account of the impact of his order flow in all markets because he is trading both directly and indirectly.

\footnotetext{
${ }^{19}$ The two-way arbitrage example is clarified in the appendix.

${ }^{20}$ For clarification on our notation, note that the informed trader in market 1 accounts for all of $x_{\mathrm{d}}^{1}$ and all of $x_{i}^{1}$, but none of $x_{i}^{2}$ or $x_{i}^{3}$.

${ }^{21}$ Buying a given quantity indirectly will not, in general, involve the same trade quantity in both indirect markets. The approximation involved in specifying the problem as in equation (6) is second-order, however - see the second part of the appendix. A convenient way of thinking about the quantities in (6) is as numbers of trades, as opposed to cash values.
} 


$$
\underset{x_{\mathrm{d}}^{3}, x_{\mathrm{i}}^{3}, x_{\mathrm{a}}^{3}}{\operatorname{aax}} E\left[x_{\mathrm{d}}^{3}\left(v^{3}-p^{3}\right)+x_{\mathrm{i}}^{3}\left(v^{3}-\tilde{p}^{3}\right)+x_{\mathrm{a}}^{3}\left(p^{3}-\tilde{v}^{3}\right)\right]
$$

where the indirect price for currency 3 is $\tilde{p}^{3} \equiv p^{1}+p^{2}$ and the arbitrage buying price for currency 3 purchased in the other two markets is $\tilde{v}^{3} \equiv p^{1}+p^{2}$, the two being equal.

The first-order condition with respect to direct trading $x_{\mathrm{d}}^{3}$ is:

$$
\begin{aligned}
& E_{v^{3}}\left[v^{3}-\left\{\begin{array}{l}
\lambda_{33}\left(x_{\mathrm{a}}^{1}+x_{\mathrm{i}}^{1}+x_{\mathrm{a}}^{2}+x_{\mathrm{i}}^{2}+x_{\mathrm{d}}^{3}\right)+\lambda_{32}\left(-x_{\mathrm{a}}^{1}-x_{\mathrm{i}}^{1}+x_{\mathrm{d}}^{2}+x_{\mathrm{a}}^{3}+x_{\mathrm{i}}^{3}\right) \\
+\lambda_{31}\left(x_{\mathrm{d}}^{1}-x_{\mathrm{a}}^{2}-x_{\mathrm{i}}^{2}+x_{\mathrm{a}}^{3}+x_{\mathrm{i}}^{3}\right)
\end{array}\right\}\right] \\
& =\lambda_{33} x_{\mathrm{d}}^{3}+\left(\lambda_{13}+\lambda_{23}\right) x_{\mathrm{i}}^{3}+\left(\lambda_{13}+\lambda_{23}-\lambda_{33}\right) x_{\mathrm{a}}^{3}
\end{aligned}
$$

and the first-order condition with respect to indirect trading (one-way arbitrage) $x_{\mathrm{i}}^{3}$ is:

$$
\begin{aligned}
& E_{v^{3}}\left[v^{3}-\left\{\begin{array}{l}
\lambda_{13}\left(x_{\mathrm{a}}^{1}+x_{\mathrm{i}}^{1}+x_{\mathrm{a}}^{2}+x_{\mathrm{i}}^{2}+x_{\mathrm{d}}^{3}\right)+\lambda_{23}\left(x_{\mathrm{a}}^{1}+x_{\mathrm{i}}^{1}+x_{\mathrm{a}}^{2}+x_{\mathrm{i}}^{2}+x_{\mathrm{d}}^{3}\right) \\
\lambda_{12}\left(-x_{\mathrm{a}}^{1}-x_{\mathrm{i}}^{1}+x_{\mathrm{d}}^{2}+x_{\mathrm{a}}^{3}+x_{\mathrm{i}}^{3}\right)+\lambda_{22}\left(-x_{\mathrm{a}}^{1}-x_{\mathrm{i}}^{1}+x_{\mathrm{d}}^{2}+x_{\mathrm{a}}^{3}+x_{\mathrm{i}}^{3}\right) \\
\lambda_{11}\left(x_{\mathrm{d}}^{1}-x_{\mathrm{a}}^{2}-x_{\mathrm{i}}^{2}+x_{\mathrm{a}}^{3}+x_{\mathrm{i}}^{3}\right)+\lambda_{21}\left(x_{\mathrm{d}}^{1}-x_{\mathrm{a}}^{2}-x_{\mathrm{i}}^{2}+x_{\mathrm{a}}^{3}+x_{\mathrm{i}}^{3}\right)
\end{array}\right\}\right] \\
& =\left(\lambda_{31}+\lambda_{32}\right) x_{\mathrm{d}}^{3}+\left(\lambda_{11}+\lambda_{12}+\lambda_{21}+\lambda_{22}\right) x_{\mathrm{i}}^{3}+\left(\lambda_{11}+\lambda_{12}+\lambda_{21}+\lambda_{22}-\lambda_{31}-\lambda_{32}\right) x_{\mathrm{a}}^{3}
\end{aligned}
$$

Finally, the first order condition with respect to two-way arbitrage $x_{\mathrm{a}}^{3}$ is:

$$
\begin{aligned}
& E\left[\begin{array}{c}
-\lambda_{13}\left(x_{\mathrm{a}}^{1}+x_{\mathrm{i}}^{1}+x_{\mathrm{a}}^{2}+x_{\mathrm{i}}^{2}+x_{\mathrm{d}}^{3}\right)-\lambda_{23}\left(x_{\mathrm{a}}^{1}+x_{\mathrm{i}}^{1}+x_{\mathrm{a}}^{2}+x_{\mathrm{i}}^{2}+x_{\mathrm{d}}^{3}\right)+ \\
\lambda_{33}\left(x_{\mathrm{a}}^{1}+x_{\mathrm{i}}^{1}+x_{\mathrm{a}}^{2}+x_{\mathrm{i}}^{2}+x_{\mathrm{d}}^{3}\right)-\lambda_{12}\left(-x_{\mathrm{a}}^{1}-x_{\mathrm{i}}^{1}+x_{\mathrm{d}}^{2}+x_{\mathrm{a}}^{3}+x_{\mathrm{i}}^{3}\right)- \\
\lambda_{22}\left(-x_{\mathrm{a}}^{1}-x_{\mathrm{i}}^{1}+x_{\mathrm{d}}^{2}+x_{\mathrm{a}}^{3}+x_{\mathrm{i}}^{3}\right)+\lambda_{32}\left(-x_{\mathrm{a}}^{1}-x_{\mathrm{i}}^{1}+x_{\mathrm{d}}^{2}+x_{\mathrm{a}}^{3}+x_{\mathrm{i}}^{3}\right)- \\
\lambda_{11}\left(x_{\mathrm{d}}^{1}-x_{\mathrm{a}}^{2}-x_{\mathrm{i}}^{2}+x_{\mathrm{a}}^{3}+x_{\mathrm{i}}^{3}\right)-\lambda_{21}\left(x_{\mathrm{d}}^{1}-x_{\mathrm{a}}^{2}-x_{\mathrm{i}}^{2}+x_{\mathrm{a}}^{3}+x_{\mathrm{i}}^{3}\right)+ \\
\lambda_{31}\left(x_{\mathrm{d}}^{1}-x_{\mathrm{a}}^{2}-x_{\mathrm{i}}^{2}+x_{\mathrm{a}}^{3}+x_{\mathrm{i}}^{3}\right)
\end{array}\right] \\
& =\left(\lambda_{31}+\lambda_{32}\right) x_{\mathrm{d}}^{3}+\left(\lambda_{11}+\lambda_{12}+\lambda_{21}+\lambda_{22}\right) x_{\mathrm{i}}^{3}+\left(\lambda_{11}+\lambda_{12}+\lambda_{21}+\lambda_{22}-\lambda_{31}-\lambda_{32}\right) x_{\mathrm{a}}^{3}
\end{aligned}
$$

These conditions are interpretable as follows: the informed trader stops building his position at the point where the expected gap between price and fundamental value is equal to the full impact on price from the informed trader's trades (the right-hand side in both cases representing that full impact on price). For the first two equations, the "fundamental value" is the inside information to which the trader has access with regard to the value of the $¥ / €$ pair. For the last equation, the fundamental value is common knowledge: namely that deviations from triangular arbitrage should be precisely zero. Nevertheless, the trader does not drive such 
deviations precisely to zero: the expected deviation on the left hand side is indeed zero but even two-way arbitrage is costly because of the price impact of order flow.

The signal $v^{3}$ provides no information about the other two traders' demands because of the orthogonality of the innovations. Consequently their expected value is zero. Using the above first order conditions, we can then solve for the optimal trading pattern of the $¥ / €$ investor:

$$
\begin{gathered}
x_{\mathrm{d}}^{3}=\left(\frac{\left(\lambda_{31}+\lambda_{32}\right)\left(\lambda_{13}+\lambda_{23}+\lambda_{33}\right)-2 \lambda_{33}\left(\lambda_{11}+\lambda_{12}+\lambda_{21}+\lambda_{22}\right)}{2 \lambda_{33}\left\{\left(\lambda_{13}+\lambda_{23}\right)\left(\lambda_{31}+\lambda_{32}\right)-\lambda_{33}\left(\lambda_{11}+\lambda_{12}+\lambda_{21}+\lambda_{22}\right)\right\}}\right) v^{3} \\
x_{\mathrm{i}}^{3}=\left(\begin{array}{l}
-\left\{\begin{array}{l}
\lambda_{13}^{2}+\lambda_{23}^{2}+\lambda_{23}\left(\lambda_{31}+\lambda_{32}-2 \lambda_{33}\right)+\lambda_{13}\left(2 \lambda_{23}+\lambda_{31}+\lambda_{32}-2 \lambda_{33}\right) \\
-2 \lambda_{33}\left(\lambda_{11}+\lambda_{12}+\lambda_{21}+\lambda_{22}\right)+\lambda_{33}\left(\lambda_{31}+\lambda_{32}+\lambda_{33}\right)
\end{array}\right\} \\
2 \lambda_{33}\left\{\left(\lambda_{13}+\lambda_{23}\right)\left(\lambda_{31}+\lambda_{32}\right)-\lambda_{33}\left(\lambda_{11}+\lambda_{12}+\lambda_{21}+\lambda_{22}\right)\right\}
\end{array}\right) v^{3} \\
x_{\mathrm{a}}^{3}=\left(\begin{array}{l}
-\left\{\begin{array}{l}
\left(\lambda_{13}+\lambda_{23}\right)\left(\lambda_{13}+\lambda_{23}+\lambda_{31}+\lambda_{32}\right) \\
-\lambda_{33}\left(2 \lambda_{11}+2 \lambda_{12}+2 \lambda_{21}+2 \lambda_{22}+\lambda_{13}+\lambda_{23}-\lambda_{31}-\lambda_{32}\right)
\end{array}\right\} \\
2 \lambda_{33}\left\{\left(\lambda_{13}+\lambda_{23}\right)\left(\lambda_{31}+\lambda_{32}\right)-\lambda_{33}\left(\lambda_{11}+\lambda_{12}+\lambda_{21}+\lambda_{22}\right)\right\}
\end{array}\right) v^{3}
\end{gathered}
$$

We are now in a position to use the model to address a number of fundamental questions regarding vehicle currency use. ${ }^{22}$ Specifically, ratios of the expressions in equations (8)-(10) pin down the relative intensity of direct, indirect, and arbitrage trading within and across currencies.

\section{(i) What determines the choice of direct versus vehicle trade?}

Consider the decision whether to trade directly in market 3, the $¥ / €$ market, or to use the $\$$ as a vehicle for arbitrage trading, both one and two-way. The total of arbitrage trading is the sum of $x_{\mathrm{i}}^{3}$ in equation (9) and $x_{\mathrm{a}}^{3}$ in equation (10). This is:

$$
x_{\mathrm{i}}^{3}+x_{\mathrm{a}}^{3}=\left(\frac{\lambda_{13}+\lambda_{23}-\lambda_{33}}{2\left\{\left(\lambda_{13}+\lambda_{23}\right)\left(\lambda_{31}+\lambda_{32}\right)-\lambda_{33}\left(\lambda_{11}+\lambda_{12}+\lambda_{21}+\lambda_{22}\right)\right\}}\right) v^{3}
$$

\footnotetext{
${ }^{22}$ To assist the reader, the derivation of equations (8)-(12) is available in the form of a Mathematica notebook. Analogous solutions for the other two traders are available in the same format.
} 
The ratio of arbitrage to direct $¥ / €$ trading is equation (11) divided by (8):

$$
\frac{x_{\mathrm{i}}^{3}+x_{\mathrm{a}}^{3}}{x_{\mathrm{d}}^{3}}=\frac{\lambda_{33}\left(\lambda_{13}+\lambda_{23}-\lambda_{33}\right)}{-2 \lambda_{33}\left(\lambda_{11}+\lambda_{12}+\lambda_{21}+\lambda_{22}\right)+\left(\lambda_{31}+\lambda_{32}\right)\left(\lambda_{13}+\lambda_{23}+\lambda_{33}\right)}
$$

This is a manifestation of a point we made in the introduction: when trades convey information, the key to vehicle-currency choice is not bid-ask spreads, but price impact (including, as is not often recognized, cross-market price impact. Simplifying, the above expression leads to the following proposition:

Proposition 1: When $\lambda_{i j}=0 \forall i \neq j$, the ratio of arbitrage to direct trade is decreasing in $\lambda_{33}$ and increasing in $\lambda_{11}+\lambda_{22}$.

This follows from equation (12). In fact, when $\lambda_{i j}=0 \forall i \neq j$ equation (12) takes a particularly simple form:

$$
\frac{x_{\mathrm{i}}^{3}+x_{\mathrm{a}}^{3}}{x_{\mathrm{d}}^{3}}=\frac{\lambda_{33}}{2\left(\lambda_{11}+\lambda_{22}\right)}
$$

Thus, the ratio:

$$
\frac{\lambda_{33}}{\lambda_{11}+\lambda_{22}}
$$

provides a relative cost measure of direct to indirect trading (euro/yen market). Note that the condition that $\lambda_{i j}=0 \forall i \neq j$ still leaves room for flow originating in market 2 (i.e., from the market-2 informed trader) to affect order flow and price in market 1, e.g., via the indirect trades routed through market 1 . This condition on the $\lambda_{i j}$ describes a setting in which the marketmaker in a given market, say market 1, finds flows realized in markets 2 and 3 to be redundant for estimating $v^{1}$. Because value innovations are independent, this means that he finds them redundant for estimating the market-1 informed trader's trades (given observation of flow in his own market). From equation (6), a sufficient condition for this is that the expected value of 
$x_{i}^{1}+x_{a}^{1}$ in markets 2 and 3 is zero, conditional on having observed total flow in all three markets. ${ }^{23}$

\section{(ii) What determines the relative importance of a currency as a vehicle?}

To answer this we need to compare use of the dollar as a vehicle (i.e., arbitrage $¥ / €$ trading via the dollar) to use of the euro as a vehicle (i.e., arbitrage $¥ / \$$ trading via the euro). Equation (11) provides an expression for the former. The analogous expression for the euro is:

$$
x_{\mathrm{i}}^{2}+x_{\mathrm{a}}^{2}=\left(\frac{\lambda_{32}-\lambda_{12}-\lambda_{22}}{2\left\{\left(\lambda_{12}-\lambda_{32}\right)\left(\lambda_{21}+\lambda_{23}\right)-\lambda_{22}\left(\lambda_{11}-\lambda_{13}-\lambda_{31}+\lambda_{33}\right)\right\}}\right) v^{2}
$$

The ratio of arbitrage trading through the dollar relative to the euro is equation (11) divided by (14):

$$
\frac{\left\{\left(\lambda_{21}-\lambda_{23}\right)\left(\lambda_{12}-\lambda_{32}\right)-\lambda_{22}\left(\lambda_{11}-\lambda_{13}-\lambda_{31}+\lambda_{33}\right)\right\}\left(\lambda_{13}+\lambda_{23}-\lambda_{33}\right)}{\left\{\left(\lambda_{13}+\lambda_{23}\right)\left(\lambda_{31}+\lambda_{32}\right)-\lambda_{33}\left(\lambda_{11}+\lambda_{12}+\lambda_{21}+\lambda_{22}\right)\right\}\left(\lambda_{32}-\lambda_{12}-\lambda_{22}\right)}\left(\frac{v^{3}}{v^{2}}\right)
$$

This leads to the following proposition:

Proposition 2: When $\lambda_{i j}=0 \forall i \neq j$, vehicle trading through the dollar relative to the euro is increasing in $\lambda_{33}$ and decreasing in $\lambda_{22}$.

This follows from equation (15). In fact, when $\lambda_{i j}=0 \forall i \neq j$ equation (15) takes a particularly simple form:

$$
x_{\mathrm{i}}^{2}+x_{\mathrm{a}}^{2}=\frac{\lambda_{11}+\lambda_{33}}{\lambda_{11}+\lambda_{22}}
$$

Again, the result is intuitive and appealing: the vehicle role of a currency is determined by the relative price impact of its indirect trades. The lower that price impact, the more the currency will be used as a vehicle. It is worth noting that our analysis allows for indirect trades to take place

\footnotetext{
${ }^{23}$ As an empirical matter, equations (12) and (13) are nearly equivalent-see section 3.
} 
through all currencies. ${ }^{24}$ There is no one vehicle currency, just different degrees of "vehicleness". A natural definition of the relative vehicleness of the dollar vis-a vis the euro is: ${ }^{25}$

$$
\frac{\lambda_{11}+\lambda_{33}}{\lambda_{11}+\lambda_{22}}
$$

\section{(iii) Does the choice between direct and indirect trade affect the informativeness of prices?}

This is an important question, one that never arose within the two traditional approaches to currency competition. The answer boils down to whether direct and indirect trades reveal the same amount of information.

Proposition 3: Whether transactions are executed directly or indirectly affects the equilibrium levels of the exchange rates.

In general a marketmaker facing order flow from indirect trading cannot recover the solution that would have resulted if order flow contained only direct trade. The logic underlying this is clear: the different markets involve different noise realizations, so there is no way to arrive at the same inferences from direct and indirect trade.

\section{(iv) What parameters determine whether one of the markets shuts down altogether?}

In the traditional market-size and marketmaker-risk approaches to international currencies, the conditions under which one of the three markets in a currency triangle shuts down are well known. (Krugman 1980 calls this total indirect exchange, i.e., no direct exchange between a currency pair takes place.) For example, total indirect exchange is more likely in Krugman's analysis when: (1) the balance of real trade between the two missing-market countries is closer to zero, (2) the balance of real trade between each of the two missing-market countries and the third country is further from zero, and (3) the rate at which transaction costs fall with market size is high (see, e.g., Krugman 1980, equations 9 and 10).

The conditions under which the whole market shuts down in information models are quite different. The essential parameters in information models, including ours, are those governing the degree of information asymmetry (see Glosten and Milgrom 1985, Glosten 1989, and

\footnotetext{
${ }^{24}$ This is different from most existing theory. Exceptions include Krugman (1984) and Hartmann (1998), both of whom consider more than one vehicle currency in a many-currency world (e.g., the legacy DM as a regional European vehicle). Nevertheless, the concentrating force of market-size economies in their models is quite different from the dispersing force — avoidance of price impact—identified here.

${ }^{25} \mathrm{We}$ also compare equations (15) and (16) in the empirical section below.
} 
Bhattacharya and Spiegel 1991). If information asymmetry in a given market becomes too high, then it is no longer possible for the marketmaker to find a price at which the market clears and he expects to earn zero profit. When the marketmaker exits, no liquidity is provided, and the market shuts down. In terms of parameter values, the shutting down of a market-which in our model corresponds to total indirect exchange - is more likely when: (1) the variance of liquiditymotivated trade $\Sigma_{c}$ in the direct market is low, (2) the variance of fundamentals $\Sigma_{v}$ in the direct market is high, and (3) the precision of the informed traders' information in the direct market is high. ${ }^{26}$ As a matter of policy, these conditions present a radically different view on what is required to jump-start a moribund currency market. This ability to fundamentally shift perspective is one of the approach's strengths.

\section{Empirical Analysis}

$\underline{\text { Data }}$

The order flow data we use to estimate the matrix is from Electronic Broking Services (EBS), the leading foreign-exchange broker. ${ }^{27}$ These data span a full twelve-month period, 1999, and cover the world’s largest currency triangle consisting of the $\$ / €, ¥ / \$$, and $¥ / €$ markets. (There are, in fact, remarkably few currency triangles for which all three markets trade at the inter-dealer level.) Our daily exchange rate data are closing New York mid-prices: as indicated in footnote 11, they are provided by Olsen and Associates. This matches the EBS 'day' precisely which runs for 24 hours from 9pm GMT the previous evening. Saturdays and Sundays were excluded.

Our use of order flow data from an FX broker accords well with the auction-market structure of our model. (For more detail on the trading mechanics of EBS, see, e.g., Killeen et al. 2001.) The are three basic types of order flow data from spot FX markets, representing the three basic transaction types. These transaction types are brokered interdealer trades, direct interdealer trades, and customer-dealer trades. ${ }^{28}$ In 1999, trading volume in the major spot FX markets was split roughly evenly between these three categories. (Since then the brokered interdealer segment

\footnotetext{
${ }^{26}$ In our model, the third of these is not a parameter, as we assume the insider observes the fundamental with no noise. It is not difficult to relax this assumption. Note too that in models with risk aversion, the category of liquidity-motivated trades includes hedge trades.

${ }^{27}$ We measure order flow here as the cash value of buyer- minus seller-initiated trades. An alternative would be to use the net number of buys minus sells. The latter choice of order flow measure has a long tradition in empirical microstructure finance (e.g., Hasbrouck 1991). The results do not differ substantially when the numbers measure is used.

${ }^{28}$ The word dealer in this literature is synonymous with marketmaker. Customers in the FX market include all non-marketmaker participants, such as hedge funds, mutual funds, and various non-financial corporations.
} 
has taken market share from the direct interdealer segment and now represents 80 percent or more of interdealer trading; see BIS 2002.) Our use of these data accords well with the auction-market structure of our model because EBS is an auction-trading mechanism (specifically, a two-sided limit order book). In contrast, both of the two other data types correspond to trading under a dealership-market structure. Not surprisingly though, given how integrated the major spot FX markets are, order flow measured from these three different sources is strongly positively correlated. It is therefore unlikely that our use of data from only one of these sources introduces obvious selection biases. (Data for the other two transaction types over our sample for all three markets are not available.). On EBS the currency is defined so that its nominal value is typically greater than unity. Hence dollar/yen is measured in yen per dollar and the volume of trades is measured in (millions of) dollars. Similarly euro/yen is measured in yen per euro with volume measured in (millions of) euro. Eurodollar almost defied this convention for much of its short life as its value was less $\$ 1$ for a sustained period. However at its launch date, it was valued conventionally in dollars per euro and its volumes in (millions of) euro.

Table 1 provides descriptive statistics for the variables used in the estimation. These are the order flows, $\$ / €$ Flow, $¥ / \$$ Flow, $¥ / €$ Flow and the three spot returns, $\Delta p^{\$ / \epsilon}, \Delta p^{¥ / \$}$ and $\Delta p^{¥ / \epsilon}$.

\section{$\underline{\text { Results }}$}

Table 2 presents the results of estimating equation (6). The coefficients are measured in basis points, i.e. the price impact in basis points per trade. ${ }^{29}$ (The median size of a trade $\$ / €$ is about $\$ 2$ million, so a coefficient of 0.04 corresponds to a price impact of 20 basis points per billion dollars.) Note that all the coefficients are highly significant. The $\bar{R}^{2}$ statistics are all remarkably high relative to macro empirical models of log exchange rate changes (consistent with Evans-Lyons 2002b). There is some evidence that the residuals in the dollar-euro equation are negatively auto-correlated (consistent with evidence on that pair over the same period in Hau, Killeen and Moore 2002). Hausman specification tests for endogeneity of order flow (using lagged order flow as instruments) show that simultaneity is overwhelmingly rejected (not reported).

It is interesting that the matrix is obviously not symmetric. The last column measures the price impact of euro-yen trades across all three markets: the coefficients are noticeably large. The implication is that traders choosing to trade in this market are providing particularly informative signals. Returning to Proposition 1, from these estimates we can assess the relative cost of indirect to direct trading in the smallest of our triangle of markets, the $¥ / €$ market. The expression

${ }^{29}$ The figures in parentheses are t-tests of the hypothesis that the coefficient is zero. 
$\lambda_{11}+\lambda_{22}$ which measures the cost of indirect trade is estimated at 0.063 . By contrast, the point estimate of the cost of direct trade $\lambda_{33}$ is 0.131 . The relative cost of direct to indirect trading in the euro/yen market is, using equation (13):

$$
\frac{\lambda_{33}}{\lambda_{11}+\lambda_{22}}=\frac{0.131}{0.063}=2.09
$$

That direct trading is so costly is consistent with the idea that traders route some of their trades through this market only when their trading is particularly aggressive, which is when the signalto-noise ratio in their trades is particularly high (a point which is, of course, relying on a richer model than that in section 1 in that it includes time-varying trading intensity). By contrast, the relative cost of direct to indirect trading in the $¥ / \$$ and $€ / \$$ markets is less than unity at 0.24 and 0.15 respectively. In these two markets, direct trading is the norm because it is less costly in terms of price impact.

Interestingly, though, our model does predict that some indirect trading will still occur in equilibrium, even though intuition (and past modes of analyzing vehicle trading) would rule it out. The reason is that price impact needs to be appreciated as a "system": Indirect trading that might appear too costly when evaluated in isolation may not be too costly at from the system perspective.

Proposition 2 suggests that the relative vehicle role of a currency is determined by the relative price impact of its indirect trades. The measure of the relative vehicleness of the dollar relative to the euro provided by our estimates is, using equation (16):

$$
\frac{\left(\lambda_{11}+\lambda_{33}\right)}{\left(\lambda_{11}+\lambda_{22}\right)}=\frac{0.157}{0.063}=2.5
$$

The euro was thus a good deal less attractive in 1999 as a vehicle than the dollar: the combined price impact of euro trades is much higher. The analogous expression for the dollar relative to the yen is 2.67 i.e. the dollar also has a greater vehicle role than the yen. The gap is slightly wider than in the case of the euro. Overall, the estimates confirm that the vehicle role of the three currencies is ranked as $\$, €$ and $¥$, respectively. The surprising aspect is that the vehicle role of 
the $€$ was only marginally more important than that of the $¥$. Both are still overshadowed by the US dollar.

We can use the model to further strengthen these insights. Instead of using the abbreviated measure in equation (13) for the relative cost of direct to indirect trading, we calculate the complete measure provided by equation (12). This yields $0.8,0.08$ and 0.07 for the $€ / ¥, ¥ / \$$ and $€ / \$$ markets respectively. The striking feature is that neither the ranking nor the relationship between the measures for the three markets differs from the estimates in equation (17) and the paragraph that follows it. A similar point can be made about the relative vehicleness of the three currencies. Instead of using equations (16) and (18), we can appeal to the precise measure provided by the theory in equation (15). This tells us that the $\$$ is 2.61 times more likely to be used as a vehicle than the $€$ and 2.28 times more likely to be used than the yen. The overall picture is unchanged: the dollar is dominant and there is little to choose between the euro and the yen. 


\section{Conclusions}

It would be heroic of us to contend that transaction costs arise wholly due to adverse selection, as they do in our information model. They do not. Our objective here is to provide a first analysis of how the presence of dispersed information can affect international currency competition and the pattern of cross-currency exchange. To isolate the new forces at work, our analysis does not include pure market-size effects nor marketmaker-risk effects on transaction costs. To the extent our information approach resonates, integration with these two earlier approaches is a natural next stage.

Our approach brings two fresh elements to existing work focusing on market size and marketmaker risk. First, we recognize that transaction flows play an important role beyond market size in that they also convey price-relevant information. Given these flows are empirically a first-order driver of exchange rate adjustment, this element is surely important for analyzing international currency competition. Second, our analysis shows that the operative flow concept for understanding the information dimension is order flow, as opposed to the flow concept stressed by the traditional analysis, namely real trade (or balance of payments) flows. Real trade flows are but a small component of currency transaction flows. Put another way, the analysis shows that it is not the gross amount of trading that matters but rather its composition. The mix matters. This point is absent from the existing literature.

Consider the following example of how neglecting this information role of transactions can affect international currency competition. When the euro was launched, most people felt the new currency would enjoy reduced transaction costs (relative to those for the DM), thereby increasing the international role of the euro relative to that of the dollar. But Hau, Killeen, and Moore $(2002 a, b)$ show that relative to those for the DM, euro transaction costs increased. The explanation they offer turns on a structural shift relating to the information role of transactions. Specifically, they argue that introduction of the euro caused higher spreads because it increased the information content of order flow by eliminating a particular source uninformative trading (the inventory management trades of marketmakers in the now-defunct Euro-zone cross-rate markets like FF/DM). Thus, their model, too, stresses the transaction mix (versus total volume).

Our analysis of vehicle currency determination leads to two powerful results. First, exchange rate levels are actually affected by whether transactions are executed directly versus indirectly; these trading methods simply do not reveal the same information. This possibility, even if obvious given the information framework, was not considered in earlier work. Second, our model provides a new understanding for why there are so few currency triangles for which a 
significant market exists in all three legs (the dollar-euro-yen triangle we study here being a notable exception). The conditions leading to the absence of direct trade in our model are of a completely different nature than those outlined by Krugman. What are the welfare consequences of having only two tradable legs to a currency triangle? And what role might policy play to increase this likelihood of full triangle trading? These are promising directions for further analytical work.

Though our model's predictions are rather strong, they are nevertheless borne out in the data. Specifically, we find that transactions affect prices across markets, as the information approach predicts. More strikingly, the estimated matrix of price-impact coefficients exhibits precisely the linear dependence predicted by our model. As an empirical matter, we view this latter result as remarkably improbable. Taken together, the results provide considerable support for the general premises of the approach.

One policy implication that derives from the premises of the approach is that what matters is not the total amount of trading (as is the focus of the existing international-currency literature), but the composition of trading. For example, one might ask whether the US dollar's current dominance as an international currency is structural. The answer from the model is that dominance depends on three key parameters: (1) the uninformative-trade variances $\Sigma_{c}$, (2) the fundamental variances $\Sigma_{v}$, and (3) the informed traders' informational precisions. Knocking the dollar from its dominant role would need to involve changes in one or more of these parameters. Policy choices certainly affect the first two of these. (For example, sterilized intervention and other officially directed trading will affect the uninformative-trade variances $\Sigma_{c}$.) The third of these has more to do with market-driven institutional realities than it does with policy (e.g., large banks privately observing more order flow than small banks).

Finally, to those who are concerned that the Kyle framework is inappropriate for the foreign exchange market, we pose the following question: do you believe that the largest players in this market (e.g., large commercial banks, hedge funds) trade strategically in order to minimize their price impact? For anyone who has observed these markets, the answer is a clear yes. This is precisely what the Kyle model is designed to capture. Of course, the model should be viewed as metaphoric in that the better-informed players do not actually see fundamentals without noise. But adding noise to the informational advantage of the better-informed players would not change the model's solution qualitatively. The model is, in fact, much more broadly applicable than the reference to "insider" trading in the title of Kyle (1985) would suggest. 


\section{References}

Bahmani-Oskooee, M. and S. Das, 1985, Transaction costs and the interest parity theorem, Journal of Political Economy, 93: 793-799.

Bhattacharya, U., and M. Spiegel, 1991, Insiders, outsiders, and market breakdowns, Review of Financial Studies, 4: 255-282.

BIS (Bank for International Settlements), Triennial Central Bank Survey of Foreign Exchange and Derivative Market Activity, Preliminary Global Results, Table 4.

Bjønnes, G., and D. Rime, 2003, Dealer behavior and trading systems in the foreign exchange market, Journal of Financial Economics, forthcoming

Black, S., 1991, Transaction costs and vehicle currencies, Journal of International Money and Finance, 10: 512-527.

Callier, P., 1981, One way arbitrage, foreign exchange and securities markets: a note, Journal of Finance, 36: 1177-1186.

Chowdhry, B., and V. Nanda, 1991, Multimarket trading and market liquidity, Review of Financial Studies, 4: 483-511.

Clinton, K. (1988), Transactions costs and covered interest arbitrage: theory and evidence, Journal of Political Economy, 96: 358-370.

Copeland, T., and D. Galai, 1983, Information effects and the bid-ask spread, Journal of Finance, 38: 1457-1469.

Covrig, V., and M. Melvin, 2002, Asymmetric information and price discovery in the FX market: Does Tokyo know more about the yen? Journal of Empirical Finance, 9: 271-285.

Danielsson, J., R. Payne, and J. Luo, 2002, Exchange Rate Determination and Inter-Market Order Flow Effects, typescript, London School of Economics (Financial Markets Group), July.

Deardorff, A.., 1979, One way arbitrage and its implications for the foreign exchange markets, Journal of Political Economy, 87: 351-364.

De Jong, F., R. Mahieu, and P. Schotman, 1998, Price discovery in the foreign exchange market: An empirical analysis of the yen/dmark rate, Journal of International Money and Finance, 17: 5-27.

Evans, M., 2002, FX trading and exchange rate dynamics, Journal of Finance, 57: 2405-2448.

Evans, M., and R. Lyons, 2002a, Order flow and exchange rate dynamics, Journal of Political Economy, 110: 170-180.

Evans, M., and R. Lyons, 2002b, Informational integration and FX trading, Journal of International Money and Finance, 21: 807-831.

Garman, M., 1976, Market microstructure, Journal of Financial Economics, 3: 257-275.

Glosten, L., and P. Milgrom, 1985, Bid, ask, and transaction prices in a specialist market with heterogeneously informed agents, Journal of Financial Economics, 14: 71-100.

Glosten, L. 1989, Insider trading, liquidity, and the role of the monopolist specialist, Journal of Business, 62: 211-235.

Hartmann, P., 1997, The currency denomination of international trade after European Monetary Union, typescript, European Central Bank.

Hartmann, P., 1998, Currency competition and foreign exchange markets: The dollar, the yen, and the euro, Cambridge University Press: Cambridge.

Hartmann, P., 1999, Trading volumes and transaction costs in the foreign exchange market: Evidence from daily dollar-yen spot data, Journal of Banking and Finance, 23: 801-824.

Hasbrouck, J., 1991, Measuring the information content of stock trades, Journal of Finance, 46: 179-207.

Hau, H., W. Killeen, and M. Moore, 2002a, The euro as an international currency: Explaining puzzling first evidence from the foreign exchange markets, Journal of International Money and Finance, 21: 351-383. 
Hau, H., W. Killeen, and M. Moore, 2002b, Euro's forex role: How has the euro changed the foreign exchange market? Economic Policy, April, 151-191.

Hau, H., and H. Rey, 2002, Exchange rates, equity prices, and capital flows, NBER Working Paper 9398, December.

Kaul, A., and V. Mehrotra, 2002, Ticker or trade? How prices adjust in international markets, typescript, University of Alberta, June.

Killeen, W., R. Lyons, and M. Moore, 2001, Fixed versus flexible: Lessons from EMS order flow, NBER Working Paper 8491 September, Journal of International Money and Finance, forthcoming.

Krugman, P., 1980, Vehicle currencies and the structure of international exchange, Journal of Money, Credit, and Banking, 12: 503-526.

Krugman, P., 1984, The international role of the dollar: Theory and prospect, in J. Bilson and R. Marston (eds.), Exchange Rate Theory and Practice, Chicago: University of Chicago Press, 261-278.

Kyle, A., 1985, Continuous auctions and insider trading, Econometrica 53, 1315-1335.

Lyons, R., 1995, Tests of microstructural hypotheses in the foreign exchange market, Journal of Financial Economics, 39: 321-351.

Lyons, R., 2001, The Microstructure Approach to Exchange Rates, MIT Press, (chapters at faculty.haas.berkeley.edu/lyons/NewBook.html).

Matsuyama, K., N. Kiyotaki, and A. Matsui, 1993, Toward a theory of international currency, Review of Economic Studies, 60: 283-320.

Milgrom, P., and N. Stokey, 1982, Information, trade, and common knowledge, Journal of Economic Theory, 26: 17-27.

Payne, R., 2003, Informed trade in spot foreign exchange markets: An empirical analysis, Journal of International Economics, 61: 307-329.

Portes, R., and H. Rey, 1998, The emergence of the euro as an international currency, Economic Policy, 26: 307-332.

Rey, H., 2001, International Trade and Currency Exchange, Review of Economic Studies, 68: 443464.

Rime, D., 2001, Private or public information in foreign exchange markets? An empirical analysis, typescript, University of Oslo, March.

Stoll, H., 1978, The supply of dealer services in securities markets, Journal of Finance, 33: 11331151.

Zhou, R, 1997, Currency Exchange in a Random Search Model, Review of Economic Studies, 64: 289-310. 
Table 1

Summary Statistics

\begin{tabular}{|c|c|c|c|c|}
\hline Variable & Unit & Mean & $\begin{array}{l}\text { Standard } \\
\text { Deviation }\end{array}$ & $\begin{array}{c}\text { AR(1) } \\
\text { Coefficient }\end{array}$ \\
\hline$\$ / €$ Flow & $€$ millions & 515 & 1100 & 0.264 \\
\hline$¥ / \$$ Flow & \$ millions & 904 & 1351 & 0.127 \\
\hline$¥ / €$ Flow & $€$ millions & 153 & 322 & 0.133 \\
\hline$\Delta p^{\$ / €}$ & $\%$ & -0.062 & 0.586 & -0.124 \\
\hline$\Delta p^{¥ / \$}$ & $\%$ & -0.035 & 0.828 & -0.043 \\
\hline$\Delta p^{\neq / €}$ & $\%$ & -0.096 & 0.913 & 0.013 \\
\hline
\end{tabular}

For the period $5^{\text {th }}$ January 1999 to $31^{\text {st }}$ December 1999 , we report for the order flows, $\$ / €$ Flow, $¥ / \$$ Flow, $¥ / €$ Flow and the three spot returns, $\Delta \mathrm{p}^{\$ / \epsilon}, \Delta \mathrm{p}^{¥ / \$}$ and $\Delta \mathrm{p}^{¥ / \epsilon}$, the mean standard deviation and the first order autocorrelation coefficient (AR(1) coefficient). There are 259 observations corresponding to all Mondays to Fridays inclusive. The first observation is lost to differencing 
Table 2

The matrix of price impact coefficients

\begin{tabular}{|c|c|c|c|c|c|}
\hline & \multicolumn{3}{|c|}{ Regressor } & \multicolumn{2}{|c|}{ Diagnostics } \\
\hline & $\$ / €$ Flow & $¥ / \$$ Flow & $¥ / €$ Flow & DW & $\overline{R^{2}}$ \\
\hline$\frac{\text { Dep. Variable }}{\Delta p^{\$ / \epsilon}}$ & $\begin{array}{c}0.026 \\
(9.4)\end{array}$ & $\begin{array}{c}-0.016 \\
(6.7)\end{array}$ & $\begin{array}{c}0.079 \\
(7.3)\end{array}$ & 2.48 & $56 \%$ \\
\hline$\Delta p^{¥ / S}$ & $\begin{array}{c}-0.016 \\
(4.5)\end{array}$ & $\begin{array}{l}0.037 \\
(10.8)\end{array}$ & $\begin{array}{c}0.056 \\
(3.2)\end{array}$ & 1.89 & $61 \%$ \\
\hline$\Delta p^{\ddagger / \epsilon}$ & $\begin{array}{c}0.011 \\
(3.2)\end{array}$ & $\begin{array}{c}0.022 \\
(5.3)\end{array}$ & $\begin{array}{c}0.131 \\
(6.0)\end{array}$ & 1.96 & $56 \%$ \\
\hline
\end{tabular}

Notes: Newey-West heteroscedasticity and serial correlation adjusted t-statistics in parentheses (lag window is 5). Estimated using Seemingly Unrelated Regressions. Sample: daily data for the year 1999. Flow data are from EBS (Electronic Broking Systems). Exchange rate data are from Olsen \& Associates. 
Figure1

DEVIATION FROM \$/€/\# TRIANGULAR PARITY

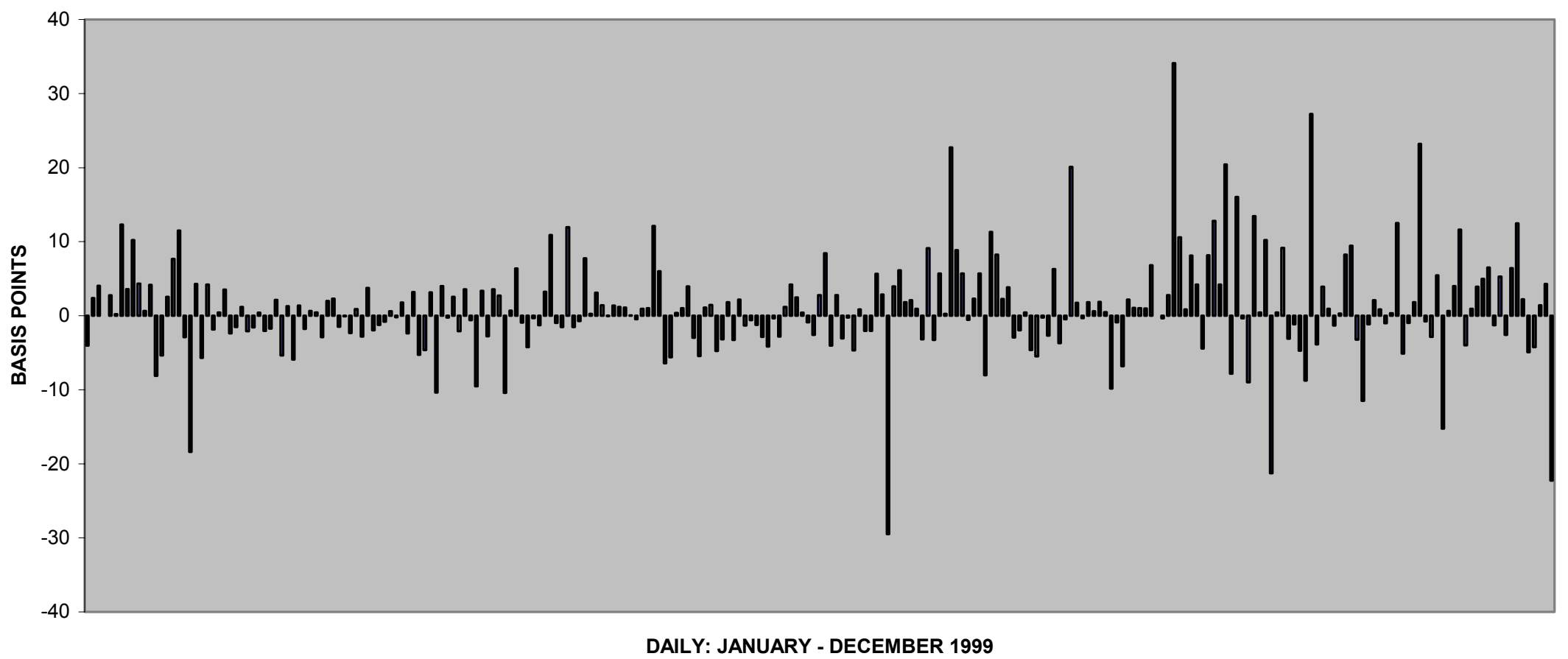




\section{Appendix}

\section{(1) Two-way arbitrage trading:}

Consider the case of a two-way (i.e., round trip) arbitrage trade in the euro-yen market. Without loss of generality, suppose $P^{\epsilon / ¥}>P^{\$ / \epsilon} P^{\$ / ¥}$. To effect two-way arbitrage, one would want to:

(1) Buy $x_{a}^{3}$ euro at price $P^{\$ / \epsilon}$ in the euro-dollar market. This costs $x_{a}^{3} P^{\$ / \epsilon}$ dollars.

(2) Fund this by selling yen for dollars in the dollar-yen market. To yield $x_{a}^{3} P^{\$ / \epsilon}$ dollars, one needs to exchange $x_{a}^{3} P^{\$ / \epsilon} P^{\$ / ₹}$ yen.

(3) Sell $x_{a}^{3}$ euro at price $P^{\epsilon / ¥}$ in the euro-yen market. This yields $x_{a}^{3} P^{\epsilon / ¥}$ yen.

The profit is $x_{a}^{3}\left(P^{€ / ¥}-P^{\$ / \epsilon} P^{\$ / ₹}\right)$ yen. Now assume that in the previous period, triangular parity obtained:

$$
\bar{P}^{€ / ¥}=\bar{P}^{\$ / €} \bar{P}^{\$ / ¥}
$$

Let us now define $\left(1+p^{i}\right) \equiv \frac{P^{i}}{\bar{P}^{i}}$. The profit, measured as \% change of yen per euro, is:

$$
\begin{aligned}
x_{a}^{3}\left(\frac{P^{\epsilon / ¥}}{\bar{P}^{\epsilon / ¥}}-\frac{P^{\$ / \epsilon} P^{\$ / \sharp}}{\bar{P}^{\$ / \epsilon} \bar{P}^{\$ / ¥}}\right) & =x_{a}^{3}\left[\left(1+p^{\epsilon / ¥}\right)-\left(1+p^{\$ / \epsilon}\right)\left(1+p^{\$ / ¥}\right)\right] \\
& =x_{a}^{3}\left[p^{\epsilon / ¥}-\left(p^{\$ / \epsilon}+p^{\$ / ¥}+p^{\$ / ¥} p^{\$ / \epsilon}\right)\right] . \\
& \approx x_{a}^{3}\left[p^{\epsilon / ¥}-\left(p^{\$ / \epsilon}+p^{\$ / ¥}\right)\right]
\end{aligned}
$$

This is the implied expression in equation (7). In the opposite case with $P^{\epsilon / ¥}<P^{\$ / \epsilon} P^{\$ / ¥}$, both the direction of trade and the unit $\%$ profit have the opposite sign. Their product remains the definition of profit.

\section{(2) Scaling order flows in equation (6)}

Consider the following example where an incremental euro is purchased using yen, but the trade is executed indirectly (through the dollar). Without loss of generality, assume that the 
matrix in equation (6) is diagonal, i.e., that there are no cross-price effects from order flow. To effect this indirect trade, one would:

(1) Buy one euro, in the euro-dollar market, when previous dollar price of euro is $P^{\$ / \epsilon}$. This purchase causes price appreciation according to $\lambda^{\$ / \epsilon}$. The cost is $P^{\$ / \epsilon}\left(1+\lambda^{\$ / \epsilon}\right)$ dollars.

(2) Fund this by buying dollars in the dollar-yen market, when the previous yen price of dollars is $P^{\$ / ¥}$. Again, trading causes price appreciation according to $\lambda^{\$ / ¥}$. A purchase of just one $\$$ in that market costs $P^{\$ / ₹}\left(1+\lambda^{\$ / \#}\right)$ yen. Consequently, to purchase the necessary $P^{\$ / \epsilon}\left(1+\lambda^{\$ / \epsilon}\right)$ dollars, it will cost $P^{\$ / \epsilon} P^{\$ / \#}\left(1+\lambda^{\$ / \epsilon}\right)\left(1+\lambda^{\$ / ₹}\right)$ yen.

The gross cost measured as a $\%$ change of yen per euro is this $\left(1+\lambda^{\$ / \epsilon}\right)\left(1+\lambda^{\$ / \#}\right)$. Taking logs, the approximate net cost is $\lambda^{\$ / \epsilon}+\lambda^{\$ / \#}$. This is the approximation implied by equation (6). Given that the $\lambda^{\prime} s$ are of the same order as returns, the approximation has negligible economic significance. 